\title{
EXAMPLE OF USING COMPLEX SYSTEM APPROACH METHODOLOGY BY DEGRADATION OF SELECTED TECHNICAL OBJECT
}

\author{
Sylvia Kusmierczak, Makovsky Martin \\ J. E. Purkyne University in Usti nad Labem, Czech Republic \\ kusmierczak@fvtm.ujep.cz
}

\begin{abstract}
Every graduate of engineering fields in his technical practice will encounter manifestations of limit states and degradation of technical objects. The consequences of these processes must be solved so as to ensure the required quality and safety, while ensuring the economic viability of the manufactured technical object. The consequences of the degradation processes of the technical objects lead not only to undesirable changes of properties and consequent shortening of the life cycle of a technical object, but also to economic losses and endangering the safety of the user of this object. Therefore, it is necessary to apply such a system approach for the evaluation of degradation processes, which will be repeatable for different types of TO and will lead to the detection of causes of degradation of TO. The methodology of a comprehensive approach to the degradation processes of TO has these main steps: localization and description of TO degradation manifestations; theoretical analysis of internal and external TO factors; description of the actual status of the TO and the actual conditions under which it was issued; determination of the factors that may cause boundary states and degradation processes TO; assessment of TO degradation - TO analysis using microscopic, destructive and non-destructive tests; processing results, determining causes of TO degradation; concluding conclusions to avoid the development of degradation processes of TO, resp. limitation of TO degradation. This methodology will be applied when dealing with a particular case from technical manufacturing practice. It is part of Shaft Throttle, which was made of $11 \mathrm{SMnPb} 30$ automatic steel according to CSN EN 10027-1. On this component during the manufacturing process on the surface unwanted corrosion products appeared. The aim of this article is to demonstrate to students of technical fields the application of a complex system approach methodology to solve a particular problem.
\end{abstract}

Keywords: methodology, degradation, technical objects, students.

\section{Introduction}

Every graduate of engineering disciplines in the technical practice meets with manifestations of limit states and degradation of technical objects [1-3]. The consequences of these processes must be solved in such a way as to ensure the required quality and safety, while ensuring the economic carrying capacity of the manufactured technical object. In technical practice, the accepted safety of technical object operations must be a priority, while maintaining the expected lifetime, without premature limit states or degradation. This indicator can be adhered to by a quality approach from the design of the technical object to its implementation and operation. Due to the increased performance where technical objects are overloaded (mechanically, thermally, dynamically, etc) [4;5] and increasing demands are placed on them, it is necessary to use new approach methodologies, such as the comprehensive system approach both in primary production, as well as in solving already established limit states on technical objects [6;7].

The consequences of degradation processes of technical objects lead not only to undesirable changes in the properties and consequent shortening of the TO life cycle, but also to economic losses and threats to the safety of the user of the structural unit. Therefore, it is necessary to apply a systemic approach for the evaluation of degradation processes that will be repeatable for different types of TO and will lead to the detection of the causes of technical object degradation.

The comprehensive system approach is the design and application of methodology for solving technical problems in manufacturing practice towards improving safety and economic indicators of technical objects. This systemic approach includes a scenario for solving causal problems and creating a system of essential variables.

The methodology of a comprehensive approach to the degradation processes of metallic engineering objects has the following major common steps:

- localization and description of TO degradation,

- theoretical analysis of internal and external TO factors,

- description of the actual state of the TO and the actual conditions to which the TO was exposed, 
- comparison of theoretical factors with real factors - determination of factors that can cause limit states and degradation processes of TO,

- evaluation of TO degradation - TO analysis using microscopy methods, destructive and NDT tests,

- processing results, determining the causes of TO degradation,

- conclusions to prevent the formation of degradation processes of TO, resp. reduction of TO degradation [8-14].

The aim of this article is to demonstrate to students of technical fields the application of a complex system approach methodology to solve a particular problem.

\section{Localization and description of degradation of particular TO}

The shaft throttle is a device designed to influence the amount of intake air into the engine. Fig. 1 shows a shaft throttle.

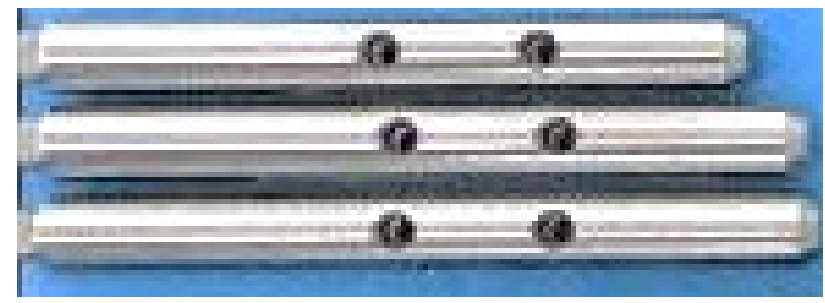

Fig. 1. Shaft throttle

Shaft throttle is made of free cutting steel 11SMnPb30 according to CSN EN 10027-1 (CSN 41 1109 marking according to CSN 42 002, 1.0715 marking according to CSN EN 10027-2).

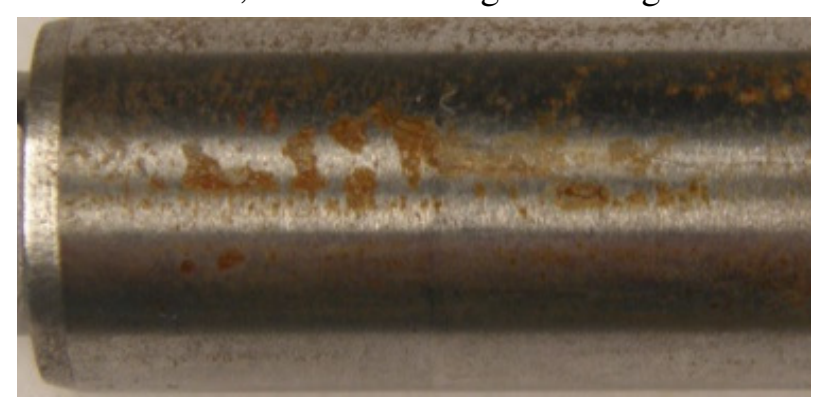

Fig. 2. Corrosion on shaft throttle

This is the occurrence of corrosion on components during the manufacturing process, Fig. 2. This occurs after grinding operation. Corrosion affects the entire surface of the part. The analyses were performed on two sample groups: OK - corrosion-free on components, NOK - surface corrosion on components.

\section{Theoretical analysis of internal and external factors of TO}

A number of factors influence the quality of blacking products, which can be divided into internal and external.

Internal factors:

- chemical composition of the material (content of harmful, alloying elements, admixtures);

- material structure (heterogeneity, different grain size, bubbles, pores);

- inclusions (type, layout, size, shape);

- internal stress (in the entire material cross-section, in the surface layers);

- surface condition of the material (roughness, surface hardening, etc.).

External factors:

- environment (temperature, humidity during storage, transport and production);

- technology used (type, parameters used); 
- used tool (material, geometry, quality, wear);

- cutting fluid (composition, age, temperature);

- washing and drying (temperature, bath concentration, soaking time, drying temperature, drying time);

- blackening (grease residue on components, concentration of blackening agent, surface roughness, blackening time, bath temperature);

- manipulation;

- human factor (manipulation, ...).

\section{Description of the actual TO status and the actual conditions to which the TO was exposed}

Part production process:

1. Delivery of semi-finished product.

2. Machining on automatic lathe - parting from the bar. 3. Machining centre: groove production, hole drilling, thread production.

3. Degreasing and washing of parts. Passivation in SurTec 53 bath. Drying at $130^{\circ} \mathrm{C}$.

4. Manual deburring and chamfering.

5. Grinding - outer cylindrical surface.

6. Corrosion protection: SurTec 533, temperature $60^{\circ} \mathrm{C}$.

7. Drying.

8. Visual inspection.

9. Packaging and dispatch for cooperation of alkaline blackening.

10. Return: with visual check.

\section{Comparison of theoretical factors with real factors}

With regard to the degradation effects, i.e. the occurrence of corrosion products on the surface of the part, it can be stated that the limit states and degradation processes are closely related to the material of the component (microstructure, chemical composition) and the surface condition of the component. Attention should be paid to degreasing, washing and drying parts that can cause the surface to wet and thereby start corrosion processes on the part surface.

\section{Evaluation of TO degradation}

Microstructure analysis. The sample was prepared by a classical metallographic procedure. The structure of the OK sample shows a large number of inclusions (Fig. 3a), with respect to the chemical composition of the material, probably manganese sulphides. In the longitudinal direction, the inclusions are oriented in the rolling direction of the blank as they are cold-formed bars. Inclusions in the longitudinal direction range from $5 \mu \mathrm{m}$ to $20 \mu \mathrm{m}$.

a)

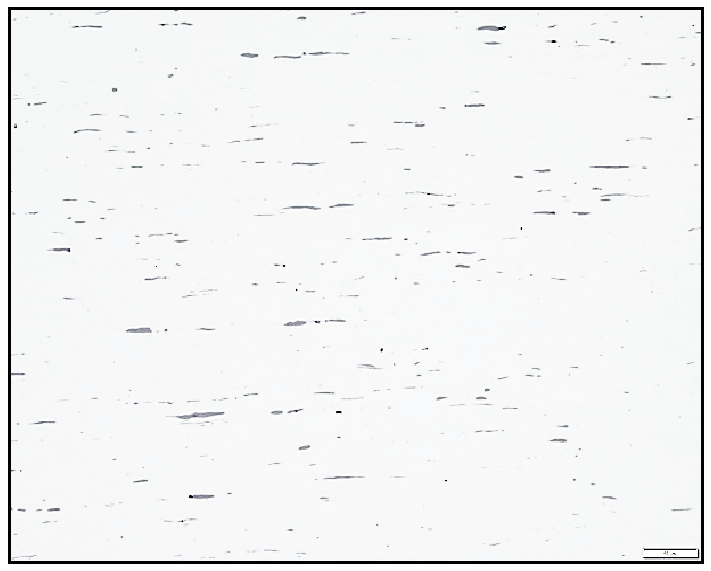

b)

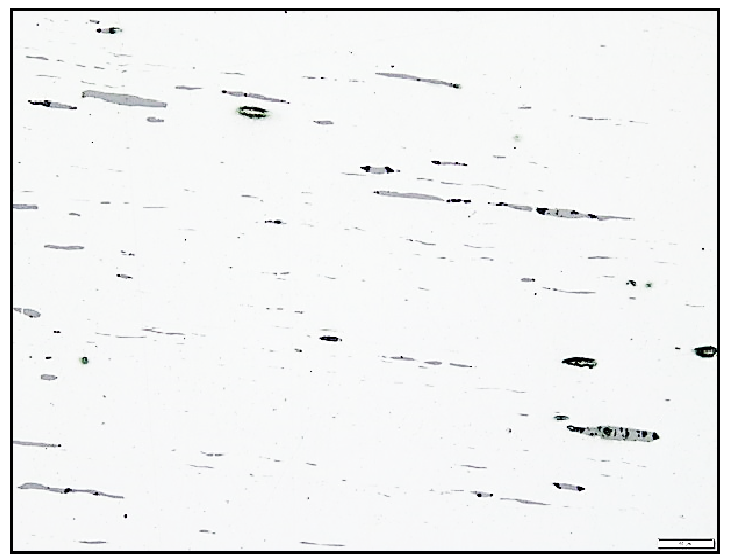

Fig. 3. Structure, longitudinal section, non-etched: $a$ - sample OK; $b$ - sample NOK

For the NOK sample, it can be observed that the inclusions are significantly larger, some cracked (Fig. 3b). The size of the inclusions ranged from $20 \mu \mathrm{m}$ to $75 \mu \mathrm{m}$. The size of the inclusions affects the 
machinability of the part and thus the resulting surface quality of the part. Surface quality is one of the basic factors affecting the corrosion resistance of the component.

The samples were then etched with Nital solution $\left(3 \% \mathrm{HNO}_{3}\right.$, alcohol). In the study of the material in the etched state (Fig. 4) it can be seen that it has a ferritic structure with perlite at the grain boundary. The structure is fine-grained and even. The detailed observation (Fig. 4b) shows that lead and bismuth particles are uniformly distributed in the base material structure to be added to the free cutting steels to increase machinability.

a)

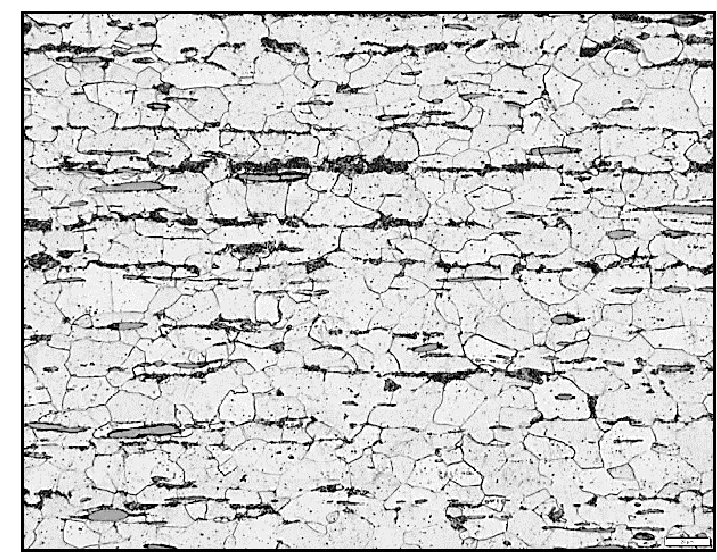

b)

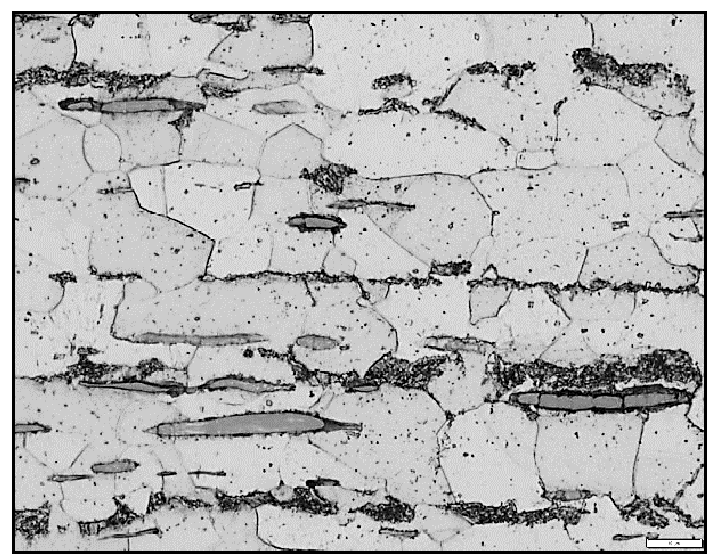

Fig. 4. Sample OK, structure in longitudinal direction, etched $3 \% \mathrm{HNO}_{3}$ : a - sample OK; b - detail

The structure of the NOK sample (Fig. 5a) has an uneven grain size compared to the OK sample. The NOK sample has a substantially coarser microstructure. The structure also exhibits large inclusions that were probably caused by processing. It is evident during detailed observation (Fig. $5 \mathrm{~b}$ ) that the inclusions have four times the size compared of the sample OK. There are also greater numbers of lead and bismuth particles evenly distributed in the material structure.

a)

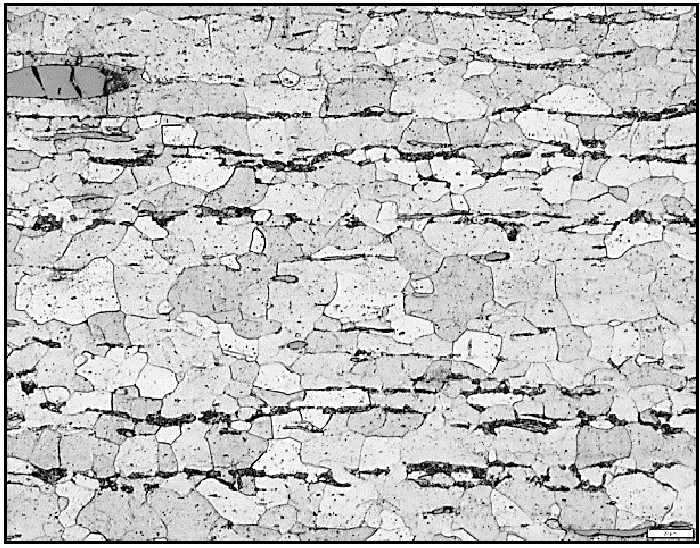

b)

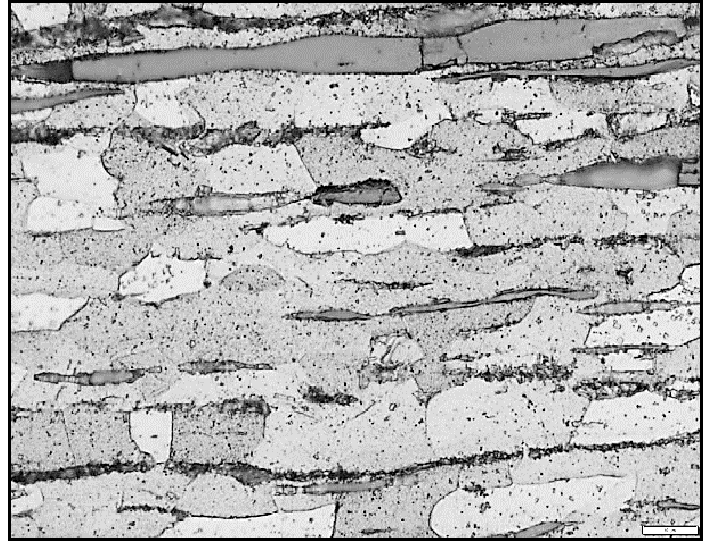

Fig. 5. NOK sample, structure in longitudinal direction, etched $3 \% \mathrm{HNO}_{3}$ : a - sample NOK; b - detail

Electron microscopy. The sample surface of OK (Fig. 6a) does not have a significant surface cohesion failure. Visually, the surface roughness of the NOK sample is higher than that of the OK sample. On the surface of the NOK sample there are areas where the surface has been interrupted (Fig. $6 \mathrm{~b})$. This has probably already appeared in the process of making bars, in cold drawing. At the point of interruption of the surface, corrosion products are evident.

Area EDX analysis. Based on the results of the areal EDX analysis, the chemical composition of corrosion products on the sample of NOK and the sample surface of OK was found (Fig. 7). The results analyzes are shown in Table 1. There is also a small amount of $\mathrm{O}$ on the surface of the sample, but its content is about 5 times smaller than on the surface of the NOK sample. Iron-based oxides have 
been formed. The high $\mathrm{C}$ content is probably the incorrectly performed degreasing in the production process.

a)

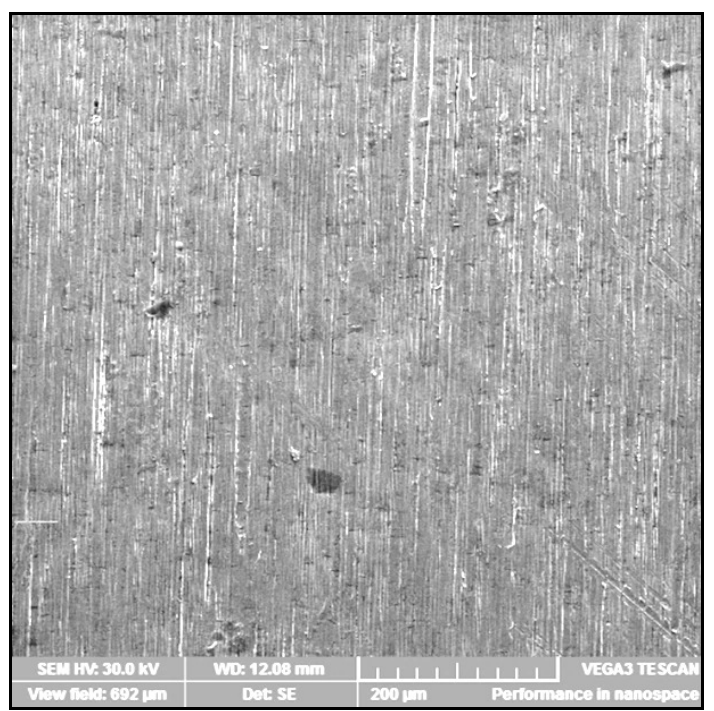

b)

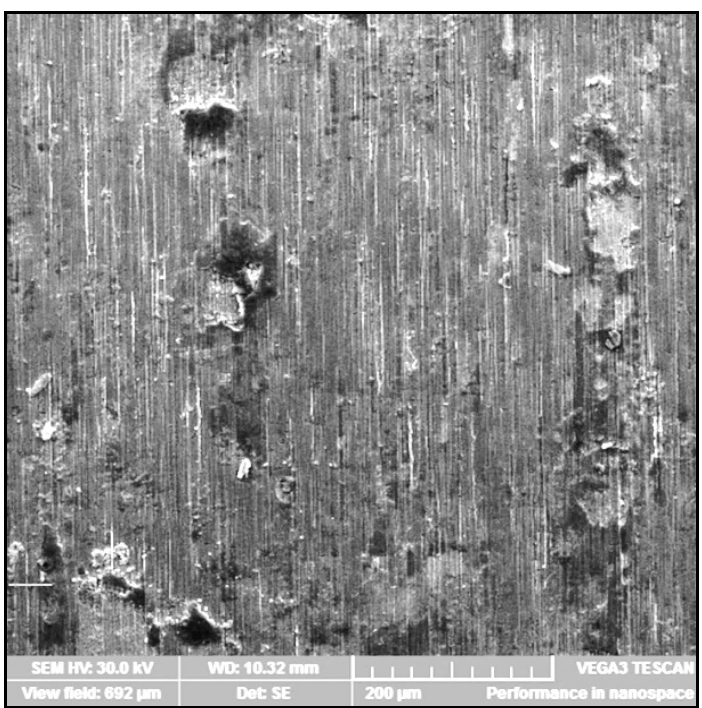

Fig. 6. Surface of components, electron microscopy: $a$ - sample OK; b - sample NOK

a)

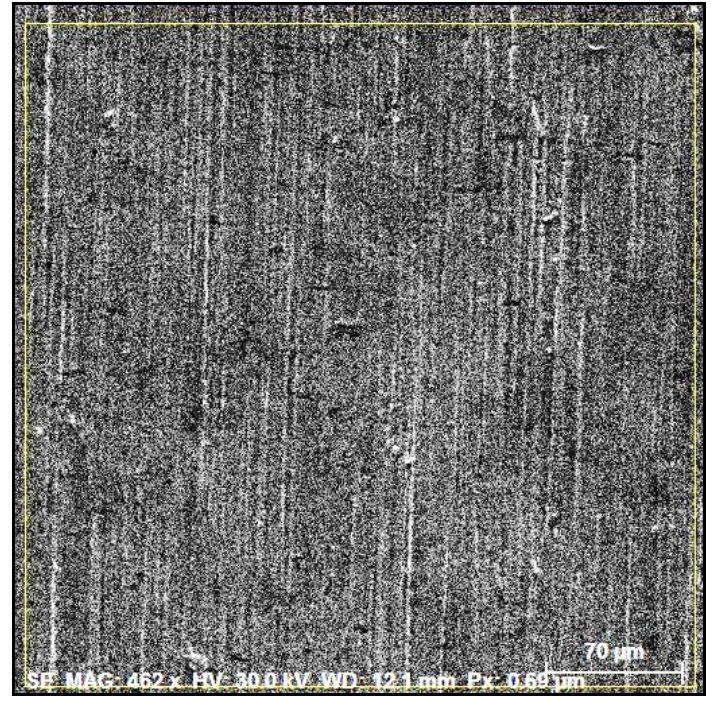

b)

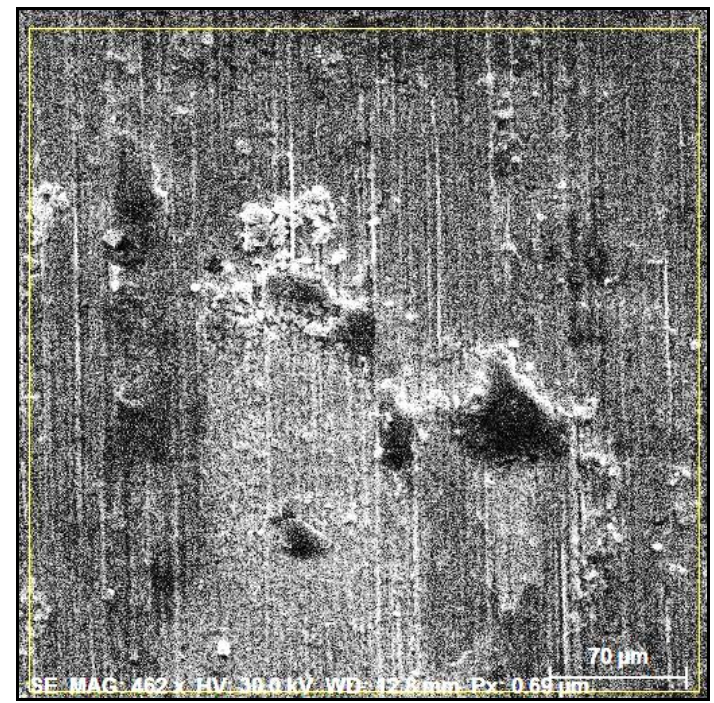

Fig. 7. Area EDX analysis, selected areas: $a$ - sample OK; $b$ - sample NOK

Table 1

Results of area EDX analysis, \%

\begin{tabular}{|c|c|c|c|c|c|c|c|c|c|c|c|c|}
\hline Sample & Fe & C & Mn & S & Mo & Pb & Bi & Al & O & Cu & Na & Ca \\
\hline OK & 66.28 & 11.95 & 12.13 & 0.02 & 5.28 & 0.50 & 0.55 & 0.12 & 2.30 & 0.09 & 0.29 & 0.01 \\
\hline NOK & 56.02 & 16.79 & 10.17 & 0.00 & 4.69 & 0.48 & 0.27 & 0.05 & 11.12 & 0.00 & 0.29 & 0.03 \\
\hline
\end{tabular}

\section{Results and discussion}

The manifestation of degradation processes was the uneven effect of corrosion products after grinding. Analyzes have shown that the structure of the investigated NOK sample contains a large number of large inclusions, which size is approximately 4 times larger than in the OK sample. Microstructural analysis showed a substantially coarser microstructure. Furthermore, it was found that corrosion was only superficial.

From the results of the surface EDX analysis it was found that there was a large difference in the content of $\mathrm{C}$ on the surface of the analyzed components. 
It follows that the occurrence of corrosion products is related both to the unsatisfactory microstructure of the semi-finished product and also to the failure to observe the working procedures in the production of the part.

\section{Conclusions}

The aim of the paper was to demonstrate to students of technical fields the application of a complex system approach methodology to solve a particular problem. A comprehensive system approach forms the approach to solving degradation processes.

1. Students of technical disciplines use this methodology as the tool and the procedure in solving real degradation manifestations on technical components.

2. Using the comprehensive system approach, students have the opportunity to discover the causes of degradation processes and then propose measures to slow down the degradation process.

\section{Acknowledgements}

The authors are grateful for the support of grant SGS FME JEPU in Ústí nad Labem for 2019.

\section{References}

[1] Varlamov, A. A., Rimshin, V.I., Tverskoi, S.Y. The General theory of degradation (2018) IOP Conference Series: Materials Science and Engineering, 463 (2), art. no. 022028.

[2] Wang, B., Huang, W., Zheng, S. Study on restoring force performance of corrosion damage steel frame beams under acid atmosphere (2018). Applied Sciences (Switzerland), 9 (1), art. no. 103.

[3] Kusmierczak, S. Evaluation of degradation of heat stressed pipelines (2015) Manufacturing Technology, 15 (6), pp. 1006-1010.

[4] Müller, M., Valášek, P. Comparison of variables influence on adhesive bonds strength calculations (2013) Manufacturing Technology, 13 (2), pp. 205-210.

[5] Náprstková, N., Cais, J., Kraus, P., Van, T.N. Tool wear evaluation of selected inserts after turning by electron microscopy (2016) Manufacturing Technology, 16 (5), pp. 1068-1073.

[6] Kusmierczak, S., Naprstkova, N. Comparison of semifinished product influence on surface degradation of forging rolls (2018) Engineering for Rural Development, 17, pp. 1372-1377.

[7] Kusmierczak, S., Majzner, T. Comprehensive approach to evaluation of degradation in chosen parts of energy equipment (2017) Engineering for Rural Development, 16, pp. 673-679.

[8] Kusmierczak, S. Methods of evaluation degraded parts (2015) Engineering for Rural Development, 14 (January), pp. 790-794.

[9] Vivas, J., Capdevila, C., Altstadt, E., Houska, M., Sabirov, I., San-Martin, D. Microstructural Degradation and Creep Fracture Behavior of Conventionally and Thermomechanically Treated $9 \%$ Chromium Heat Resistant Steel (2019) Metals and Materials International, Volume 25, Issue 2, Pages: 343-352.

[10]Zajec, B., Bajt Leban, M., Kosec, T., Kuhar, V. Legat, A., Lenart, S., Fifer Bizjak, K., Gavin, K. Corrosion Monitoring of Steel Structure Coating Degradation (2018), Tehnicki Vjesnik-Technical Gazette, Volume: 25, Issue: 5, Pages: 1348-1355.

[11] Krella, A. K., Krupa, A. Effect of cavitation intensity on degradation of X6CrNiTi18-10 stainless steel (2018) WEAR, Volume: 408, Pages: 180-189.

[12] Krechkovska, H., Student, O., Lesiuk, G., Correia, J. Features of the microstructural and mechanical degradation of long term operated mild steel (2018), International Journal of Structural Integrity, Volume: 9, Issue: 3, Pages: 296-306, Special Issue: SI

[13]Zvirko, D. D. Electrochemical Methods for the Evaluation of the Degradation of Structural Steels Intended for Long-Term Operation (2017), Materials Science, Volume: 52, Issue: 4, Pages: 588594.

[14]Lach, T., Byun, T.S., Leonard, K. J. Mechanical property degradation and microstructural evolution of cast austenitic stainless steels under short-term thermal aging (2017), Journal of Nuclear Materials, Volume: 497, Pages: 139-153. 